\title{
Pràctiques espacials de supervivència realitzades per travestis i dones trans llatinoamericanes a la ciutat de Barcelona*
}

\author{
Marcio Jose Ornat \\ Joseli Maria Silva \\ Universidade Estadual de Ponta Grossa. Department of Geosciences \\ geogenero@gmail.com \\ joseli.genero@gmail.com
}

\author{
Alides Baptista Chimin Junior \\ Universidade Estadual de Centro-Oeste. Campus Irati \\ alides.territoriolivre@gmail.com
}

Rebut: novembre de 2018

Acceptat: juny de 2019

Publicat: juliol de 2019

\section{Resum}

Aquesta reflexió analitza les pràctiques espacials de supervivència desenvolupades per travestis $^{1}$ i dones trans llatinoamericanes a la ciutat de Barcelona. Espanya va rebre una gran inversió després de la seva entrada a la Comunitat Europea l'any 1986, la qual cosa li va permetre gaudir d'un gran creixement econòmic. El diferencial espacial que va produir aquesta situació va constituir un element d'atracció de travestis i de dones trans llatinoamericanes cap a aquest país. No obstant això, la gran recessió espanyola desencadenada per les turbulències financeres dels anys 2007 i 2008 va generar un moviment de retorn de les persones migrants. Tot i que gran part de la comprensió dels fluxos migratoris entre països estigui relacionada amb el funcionament del mercat laboral, tractant-se de travestis $\mathrm{i}$ de dones trans, el lucre de la prostitució a Espanya forma part de les pràctiques espacials de supervivència. Davant d'això, és de gran importància entendre aquest fenomen, ja que està relacionat amb els sistemes d'opressió que travestis i dones trans llatinoamericanes elaboren les seves pràctiques de supervivència espacial a Barcelona.

Paraules clau: travestis; dones trans; prostitució; espai; migració

* El text ha estat traduït del portuguès al català per Maria Prats Ferret, professora del Departament de Geografia de la Universitat Autònoma de Barcelona.

1. S'ha mantingut la paraula original del portuguès travesti, utilitzada pels autors de l'article. 
Resumen. Prácticas espaciales de supervivencia de travestis y mujeres trans latinoamericanas en la ciudad de Barcelona

Este texto analiza las prácticas espaciales de supervivencia llevadas a cabo por travestis y mujeres trans latinoamericanas en la ciudad de Barcelona. España recibió una importante inversión con la entrada en la Comunidad Europea en el año 1986, lo que supuso un gran crecimiento económico. El diferencial espacial que produjo dicha situación fue un elemento relevante en la atracción de travestis y de mujeres trans latinoamericanas hacia España. Sin embargo, la gran recesión española desencadenada por la crisis financiera de los años 2007 y 2008 produjo un movimiento de retorno de las personas migrantes. Aunque gran parte de la comprensión de los flujos migratorios entre países está relacionada con el funcionamiento del mercado laboral, tratándose de travestis y mujeres trans, la rentabilidad de la prostitución en España compone prácticas espaciales de supervivencia. En vista de lo expuesto, resulta de gran importancia comprender este fenómeno, pues está relacionado con sistemas de opresión que travestis y mujeres trans latinoamericanas elaboran prácticas espaciales de supervivencia en Barcelona.

Palabras clave: travestis; mujeres trans; prostitución; espacio; migración

Résumé. Pratiques spatiales de survie menées par des travestis et des femmes trans latinoaméricaines dans la ville de Barcelone

Ce texte analyse les pratiques spatiales de survie menées par des travestis et des femmes trans latino-américaines dans la ville de Barcelone, en Espagne. L'Espagne a bénéficié d'un investissement important lors de son entrée dans la Communauté Européenne (1986), ce qui lui a valu une forte croissance économique. Le différentiel spatial de la croissance économique était un élément important pour attirer les travestis et les femmes trans latino-américaines en Espagne. Cependant, la grande récession espagnole provoquée par la crise financière de 2007/2008 a provoqué un mouvement de retour des migrants. Bien que la compréhension des flux migratoires entre les pays soit en grande partie liée au fonctionnement du marché du travail, dans le cas des travestis et des femmes trans, la rentabilité de la prostitution en Espagne compose les pratiques de survie dans l'espace. Compte tenu de ce qui précède, la compréhension de ce phénomène est considérée comme extrêmement importante, car c'est dans le dialogue avec les systèmes d'oppression que les travestis et les femmes trans latino-américaines élaborent des pratiques spatiales de survie à Barcelone.

Mots-clés: travestis; femmes trans; prostitution; espace; migration

Abstract. Spatial practices of survival by travestis and Latin American trans women in the city of Barcelona

This text analyzes the spatial practices of survival carried out by travestis and Latin American trans women in the city of Barcelona, Spain. Following the country's entry into the European Community (1986), Spain received a significant investment, leading to marked economic growth. The spatial differential of economic growth was a relevant element in the attraction of travestis and Latin American trans women to Spain. However, the great Spanish recession triggered by the financial crisis in 2007/2008 produced a return movement of migrants. Although much of the understanding of migratory flows between countries is related to the functioning of the labor market, in the case of travestis and trans women, the profitability of prostitution in Spain composes spatial survival practices. In view of the above, the understanding of this phenomenon is considered of great importance, since it is in the dialogue with systems of oppression that travestis and Latin American trans women elaborate spatial practices of survival in Barcelona.

Keywords: travestis; trans women; prostitution; space; migration 


\section{Sumari}

\author{
1. Consideracions inicials \\ 2. Prostitució i transfobia: \\ el desplaçament espacial com \\ a opció forçada
}

3. Les pràctiques espacials de supervivència de travestis i dones trans llatinoamericanes a Espanya, i més enllà

4. Consideracions finals

Referències bibliogràfiques

\section{Consideracions inicials}

L'objectiu d'aquesta reflexió és comprendre les pràctiques espacials de supervivència que elaboren travestis $\mathrm{i}$ dones trans llatinoamericanes residents a la ciutat de Barcelona després de la crisi de funcionament del sistema de capital a Espan$\mathrm{ya}^{2}$. La nostra argumentació se sustenta en els resultats de la realització de dues entrevistes semiestructurades amb persones de l'Ajuntament de Barcelona que treballen quotidianament en les temàtiques de migració, sexualitat i prostitució. Dotze diaris elaborats en els treballs de camp realitzats als carrers del districte de les Corts, als voltants del Camp Nou, estadi del Futbol Club Barcelona ${ }^{3}$, a través d'un període de voluntariat en l'organització no governamental Metges del Món Catalunya, a més de la sistematització de les dades recollides en dues webs espanyoles d'anuncis de prostitució.

Des de l'any 2006, el Grupo de Estudos Territoriais hem elaborat recerques que analitzen la vivència espacial de les persones que amb les seves vides qüestionen la pretesa naturalitat de la linealitat entre sexe, gènere i desig, que sustenta el funcionament del mecanisme del gènere (Butler, 2003; Ornat, 2009, 2013; Ornat i Silva, 2014; Silva, 2013; Silva i Ornat, 2011; Silva i Ornat, 2016a, 2016b, 2016c, 2016d; Cabral et al., 2013).

Pel que fa a la utilització en aquesta reflexió de la paraula trans, cal dir que s'utilitza correntment a la literatura anglòfona per referir-se a la categoria transgender, que s'entén que engloba una àmplia gamma de varietat de vivències trans que reconeixen el paper del sexe en la performativitat de gènere. Així, en aquesta discussió, la paraula trans es relaciona amb persones femenines que, amb les seves pràctiques sociosexuals, qüestionen la linealitat entre sexe, gènere i desig (Browne i Lim, 2010; Browne, 2004; Browne et al., 2010; Valentine, 2007; Doan, 2007; Doan 2010; Girshick, 2008; Hines, 2010; Knopp, 2004; Nash, 2010; Rooke, 2010).

D'altra banda, quan tractem de travestis, a partir de les reflexions de Silva (2009) i d'acord amb el contacte establert i amb la convivència experimentada amb travestis brasilenyes del sud, entenem que el terme travestis es refereix a una recerca constant $i$ integral de la feminitat a partir de la relació entre vestit, maquillatge, complements i comportaments socials. Però, més enllà d'això,

2. Recerca postdoctoral finançada per la Coordinació de Perfeccionament del Personal de Nivell Superior (CAPES). Procés: POS-DOC 99999.006096/2015-08.

3. Àrea de concentració de la prostitució de travestis i de dones trans llatinoamericanes. 
també té a veure amb la recerca constant de la transformació del cos a partir de la utilització d'hormones i de silicona, sense que això acabi amb una operació de transgenitalització.

Atès que parlem de la vivència espacial de travestis $\mathrm{i}$ dones trans llatinoamericanes a Barcelona, considerem que aquestes vivències dialoguen amb les formes de denominació en el lloc de destí del procés migratori. Segons Missé $(2012)^{4}$, la paraula trans engloba tres identitats a la Ciutat Comtal: transsexual, transgènere i travesti. Segons aquesta discussió, encara que aquestes tres paraules estiguin relacionades amb configuracions d'identitat específiques, referides a la pròpia divisió interna del moviment trans a Barcelona, el terme també pot ser utilitzat pels tres grups, en el sentit de la pròpia variació territorial. Tal com han afirmat Massey (2008) i McDowell (1999), les construccions d'identitat $\mathrm{i}$, en el cas d'aquesta discussió, les relacionades amb les travestis $\mathrm{i}$ les dones trans es conformen segons determinades espacialitats i temporalitats, afirmant aquestes reflexions sobre la necessitat de pensar l'espai en tant que relacional, pel fet que aquest es defineix en les pràctiques socioespacials $i$ en les relacions socials i de poder. Pel fet que cada grup defensa les seves especificitats d'autoidentificació, al llarg del text utilitzem les denominacions travestis i dones trans, d'acord amb el procés de denominació castellana relacionat amb la mujer trans, tenint en compte l'especificitat espacial d'aquesta identificació. Per tant, tal com argumenta Butler (2003), la identitat ha de ser vista com una pràctica significant, relacionada amb subjectes culturalment intel.ligibles, resultants de la vida lingüística i quotidiana.

La vivència de travestis i dones trans a Llatinoamèrica està constituïda per un conjunt d'exclusions socials i prohibicions espacials. És a través dels territoris intraurbans i discontinus de la prostitució que aquestes persones estableixen les seves pràctiques quotidianes de supervivència. Per tant, aquesta reflexió tracta de les pràctiques espacials de supervivència a Barcelona com una de les possibles derivades de recerca de conquestes territorials cada vegada més grans, que assoleixen diverses escales espacials que superen els límits municipals i nacionals llatinoamericans, i Espanya —més específicament Barcelona- és una d'aquestes destinacions.

\section{Prostitució i transfobia: el desplaçament espacial com a opció forçada}

L'Observatori de Persones Trans Assassinades (Trans Murder Monitoring TMM) és un projecte d'enquesta sistemàtica, seguiment $\mathrm{i}$ anàlisi d'assassinats de persones trans a tot el món. Va ser iniciat l'any 2009 a partir d'una col-laboració entre Transgender Europe (TGEU) i la revista Liminalis: A Journal for Sex/Gender Emancipation and Resistance. Aquell mateix any el pla es va transformar en el projecte d'investigació Transrespect versus Transphobia Worldwide, de Transgender Europe 5 (vegeu la figura 1).

4. Font: <http://fundacionbetiko.org/>.

5. <http://transrespect.org $>$. 
Figura 1. Observatori de persones trans assassinades (TMM) de Transgender Europe
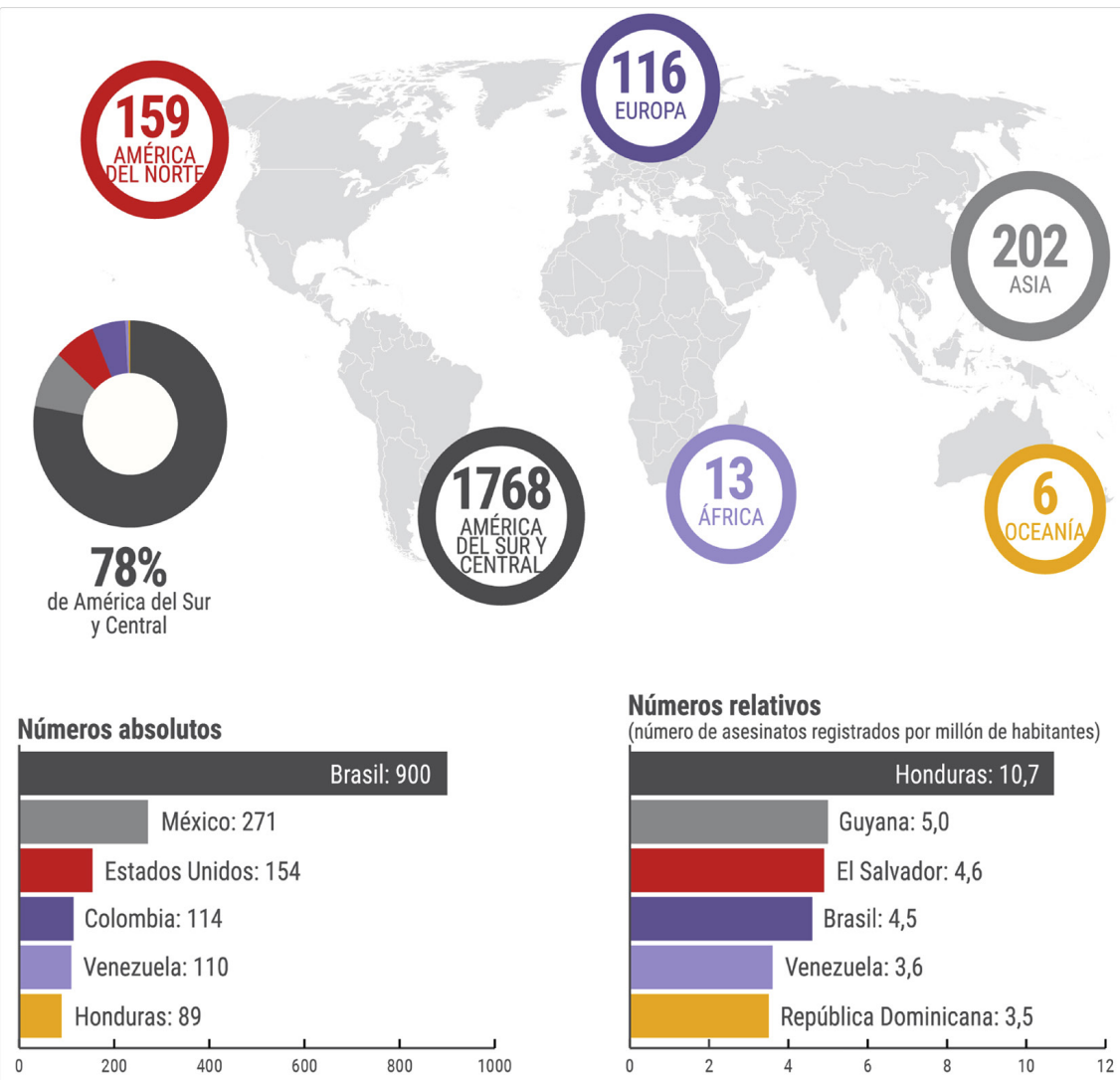

Font: $<$ https://transrespect.org/es/>.

En l'actualització de les dades realitzada el 30 de març de 2017, el projecte Transrespect versus Transphobia Worldwide va publicar les seves dades: 2.343 homicidis de persones trans, registrats als 69 països on es fa aquest seguiment, al llarg del període que va de l'1 de gener de 2008 al 31 de desembre de 2016. Assenyalem que, d'aquest total, 1.834 van tenir lloc a l'Amèrica del Sud i que el $64 \%$ de totes les persones eren treballadores sexuals.

Les dades acumulades de l'1 de gener de 2008 a 30 de setembre de 2016 ja assenyalaven un total de 2.264 morts de persones trans, en el comunicat de 20 de novembre de 2016 s'indicava que aquesta enquesta representava només la punta de l'iceberg pel que feia a la mort de persones trans arreu del món ${ }^{6}$.

6. Font: <http://transrespect.org/es/tmm-trans-day-remembrance-2016/>. Consulta: 5 d'abril de 2017. 
Bryant i Vidal-Ortiz (2008) afirmen que la manera com l'homofobia ha estat pensada per les ciències socials apunta cap al fet que es produeix en intersecció amb altres vectors de relacions de poder, com les relacions interseccionals que tenen lloc a partir de grups de renda, qüestions ètniques, racials o de nacionalitat.

Segons els autors, aquest terme va ser encunyat per George Weinberg (1972) en el seu llibre Society and the Healthy Homosexual. Tot i que va ser creat a partir de la psicologia, considerem que aquestes relacions homofobiques o, específicament en el cas de la nostra problemàtica, aquestes relacions transfobiques es produeixen a través d'espacialitats, com han evidenciat tant la discussió de Mott et al. (2002) com la de Cabral et al. (2013). Per tant, la transfobia (que és una forma específica de fobia a travestis i a dones transsexuals) s'entén com les actituds i les accions excloents, basades en consideracions sobre l'homosexualitat i els homosexuals, en les seves existències més diverses, com a desviades, malaltes, perverses, pecadores, immorals, corrompudes, etc. Per tant, tal com s'ha esmentat a la introducció d'aquesta reflexió, el nostre argument és que el canvi espacial de travestis i dones trans entre l'Amèrica Llatina i Espanya està motivat per la recerca de condicions millors de supervivència. Així doncs, aquest desplaçament espacial es configura per la composició de forces d'expulsió, relacionades de forma macro amb la transfobia, i forces d'atracció, relacionades amb un lucre més elevat, comparativament, en la prostitució a Europa i, en el cas específic d'aquesta discussió, en la prostitució a Barcelona.

Segons El Diário ${ }^{7}$, més del 90\% de les dones que exerceixen la prostitució a Espanya són migrants. D'aquest total, un $95 \%$ viu de la prostitució a causa de les estretors de les seves circumstàncies de vida. La publicació destaca que, d'aquestes, una gran part fa referència a travestis i a dones trans. Aquest conjunt de constrenyiments espacials està relacionat amb la impossibilitat d'accedir al mercat de treball, per l'exclusió que resulta de la imbricació entre el funcionament del sistema de capital i el mecanisme de gènere.

En una entrevista sobre el mateix tema publicada a El Diário, una dona trans afirma:

Nosotras [las transexuales] somos un colectivo especialmente rechazado, la gente no nos respeta del todo, los gays y las lesbianas pueden conseguir trabajo en cualquier parte, pero a nosotras prácticamente nos lanzan a la prostitución como forma de conseguir dinero ${ }^{8}$.

Segons Silva i Ornat (2014), els fluxos de desplaçament de travestis i dones trans s'estableixen segons una gran quantitat de mediacions entre elements del país d'origen, el Brasil en el cas específic de la publicació i Espanya com a destinació. Segons aquesta reflexió, els desplaçaments estan relacionats

7. Font: <http://www.eldiario.es/desalambre/inmigracion/prostitucion-inmigracion-mujeresdiscriminacion-explotacion_sexual_0_152934716.html>. Consulta: 12 de juliol de 2013.

8. Ídem. 
amb el desig de deixar el Brasil per la vivència de la transfobia, per la falta d'oportunitats financeres al país d'origen o pel desig de "ser una europea», com també per la distància espacial de la família, la qual cosa possibilita una transformació del cos sense crear conflictes. Com es veu actualment, hi ha una gestió diària dels mecanismes de regulació, una acció que forma part d'una paradoxa contínua de les relacions espacials i il.legals. La dinàmica de la migració transfronterera que realitzen aquestes persones forma part del que Sassen (2003) anomena "contrageografías de la globalización», és a dir, en certa manera forma part d'una economia subterrània, però que també utilitza la infraestructura de l'economia formal.

En el cas de l'economia formal, Espanya ha experimentat un augment de la inversió estrangera des del començament de la seva participació a la Comunitat Europea l'any 1986. En un període de dotze anys, el producte interior brut del país va créixer de 233,1 mil milions de dòlars americans a 1,5 bilions de dòlars americans 9 . Segons Silva i Ornat (2014), el fet que el Brasil no vagi experimentar aquest creixement econòmic en el mateix període ${ }^{10}$ va suposar una diferència que va constituir un element rellevant d'atracció de travestis $\mathrm{i}$ dones trans cap a Espanya (Silva i Ornat, 2014).

La gran recessió espanyola provocada per la crisi financera dels anys $2007 \mathrm{i}$ 2008 (Bentolila et al., 2012; Ferreiro i Serrano, 2012) altera el flux migratori entre aquests països. Amb una taxa de creixement del PIB l'any 2013 (Banc Mundial) del $-1,23 \%$ i una taxa d'atur del 26,6\%, el flux migratori específic entre el Brasil i Espanya va ser de 20.489 persones l'any 2018 (Instituto Nacional de Estadística ${ }^{11}$ ). El 2011, segons Juliano Corregido (2012), l'emigració va superar la immigració. Aquesta reducció dels fluxos migratoris per país d'origen es mostra al gràfic $1^{12}$.

Segons Juliano Corregido (2012), hi ha una tendència que pot perllongarse i produir una disminució de la població espanyola. És important assenyalar que, segons l'autora, només el $10 \%$ de les persones que marxen tenen aquesta nacionalitat, cosa que demostra un reflux dels corrents migratoris. Així, la crisi econòmica espanyola produeix simultàniament un moviment de retorn als països de Llatinoamèrica i una reorganització de les pràctiques de supervivència espacial a Espanya relacionades amb el lucratiu mercat de la prostitució a Barcelona.

Alguns exemples de l'organització espacial de la prostitució a la Ciutat Comtal fan referència als voltants de l'Arc de Triomf, la Rambla de Catalunya

9. Font: <http://www.worldbank.org/>

10. El període de 1991 a 2013 comptabilitza un creixement del PIB brasiler de 528,6 milers de milions de dòlars americans a 980,9 milers de milions de dòlars americans. Font: <http:// www.worldbank.org/>

11. Font: <http://www.ine.es/>

12. Font: <http://www.ine.es/jaxi/Tabla.htm?path=/t20/p277/prov/e01/10/\&file=01004. px\&L=0>. Consulta: 5 d'abril de 2017. Els països que van ser consultats estan relacionats amb les nacionalitats de travestis i de dones trans que es van trobar exercint l'activitat de la prostitució al Camp Nou, districte de les Corts, a Barcelona, a través de dos treballs de camp realitzats com a equip de l'organització no governamental Metges del Món, Catalunya, durant el període que anava de l'11 de juliol al 20 de setembre de 2016. 
Gràfic 1. Flux d'immigració exterior a Espanya segons el país de naixement del migrant, ambdós sexes

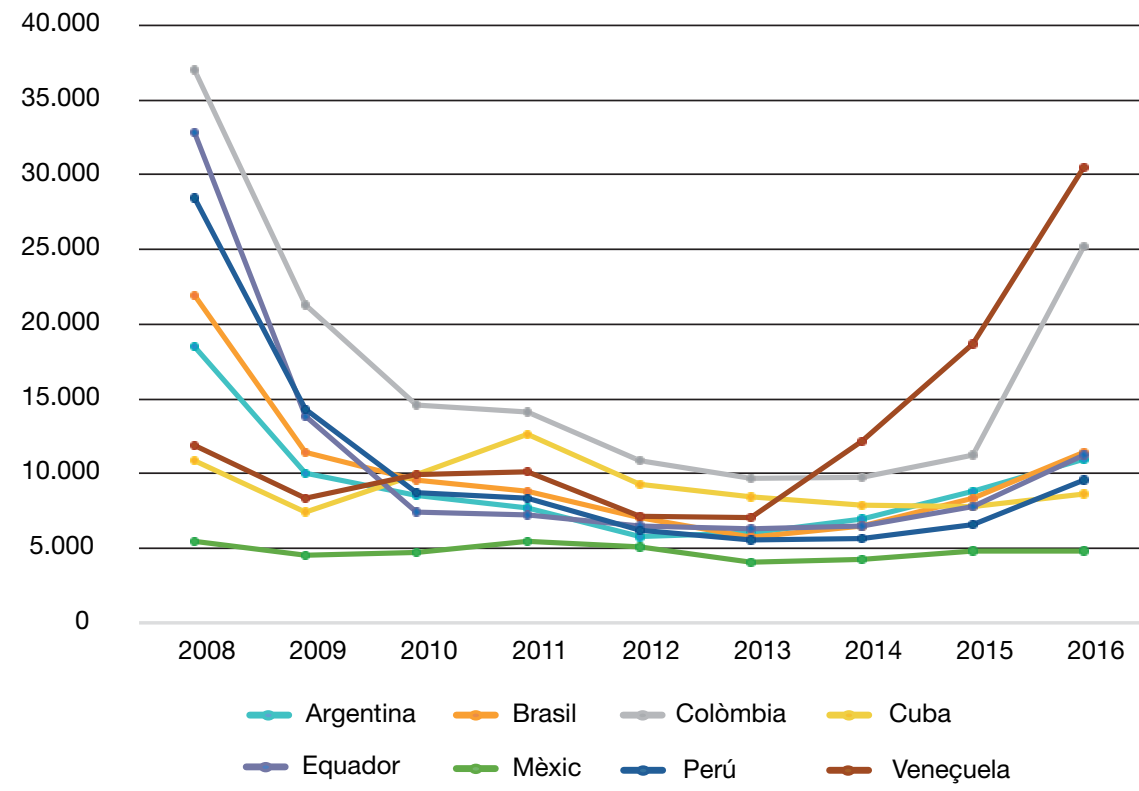

Font: $<$ https://transrespect.org/es/>.

i, en aquest estudi de cas, els carrers del barri de les Corts, als voltants del Camp Nou, estadi del Futbol Club Barcelona.

L'existència d'estratègies espacials de supervivència està relacionada amb el fet que la prostitució és un negoci molt rendible al territori espanyol. Segons l'Associació per a la Prevenció, Reinserció i Atenció de la Dona Prostituïda ${ }^{13}$, aproximadament el 39\% dels espanyols paguen per obtenir serveis sexuals. De la mateixa manera, tal com indica l' «Informe de la Ponencia sobre la Prostitución de la Comisión Mixta de los Derechos de la Mujer de las Cortes Generales" (Boletín Oficial de las Cortes Generales, 2007), la despesa diària en prostitució a Espanya era d'uns 50 milions d'euros, més de 18.000 milions d'euros a l'any. Assenyalem que, atès que aquestes dades es van publicar el 2007, és lògic assumir una disminució d'aquests valors a partir de la crisi econòmica espanyola dels anys 20072008 , la qual cosa dona lloc a canvis en el propi funcionament de la prostitució i en les pràctiques de supervivència espacial.

Tot i que una gran part de la comprensió dels fluxos migratoris entre països està relacionada principalment amb el funcionament del sistema de capitals, tal com va afirmar Mészáros (2002), i del mercat laboral, en el cas de les dones

13. Font: <http://apramp.org/>. 
travestis $\mathrm{i}$ trans, que, com s'ha vist anteriorment, difícilment troben oportunitats d'ocupació a l'Amèrica Llatina, la rendibilitat de la prostitució de travestis i dones trans a Espanya constitueix un element d'elecció espacial.

La incapacitat del sistema per funcionar segons una veritable igualtat també està relacionada amb el funcionament del gènere com a mecanisme, el qual regula les pràctiques humanes $\mathrm{i}$ crea ficcions de feminitats i de masculinitats com si fossin naturals, tal com va proposar Butler (2003). Aquest mecanisme, sostingut mitjançant la relació entre el sexe, el gènere i el desig, i alimentat per discursos mèdics, jurídics, biològics $\mathrm{i}$, segons entenem, per discursos teològics monoteistes, produeix identitats de gènere intel.ligibles i inintel.ligibles. Està relacionat amb un sistema d'intel-ligibilitat que ignora la humanitat de les persones, i entre elles les travestis i trans (Butler, 2008). Davant de la crisi econòmica espanyola i el funcionament excloent del mecanisme de gènere, les travestis $\mathrm{i}$ les dones trans llatinoamericanes desenvolupen pràctiques de supervivència espacial, lluitant per romandre en territori espanyol a través de la prostitució a Barcelona.

Més concretament, aquest text es basa en els debats geogràfics actuals sobre la complexitat de la vida quotidiana de travestis i dones trans, formada per un procés continu de prohibició espacial i de l'establiment d'estratègies espacials de supervivència que estan relacionades amb la paradoxa entre espais prohibits i espacialitats relacionades amb la prostitució (Boulevard, 2013; Lee, 2013; Nikaratty, 2013; Ornat, 2009, 2013; García Reyes, 2013; Riquelme, 2013; Silva, 2013).

L'espai prohibit s'estableix a partir de l'exercici de pràctiques reguladores realitzades per persones que ocupen el centre de les relacions de poder. Es refereix a la lògica de funcionament de les relacions de poder, ja que es «revela amb tota la seva força quan es desafia l'ordre, i els intents de transgressió de l'ordre revelen els límits espacials que no s'han de superar per mantenir l'ordre» (Silva, 2013: 159). Aquest ordre està relacionat, en la vida de travestis i dones trans, amb el funcionament del gènere com a mecanisme (Butler, 2003), com a matriu excloent.

Segons Butler (2003), aquesta matriu, que produeix identitats de gènere coherents, exigeix la producció simultània d'éssers abjectes. Precisament, l'autora anomena abjectes aquelles persones que viuen a les zones invisibles $\mathrm{i}$ inhabitables de la vida social $i$, des del nostre punt de vista, a través dels espais inhabitables. És gent que no gaudeix dels mateixos drets, que viu per sota del que s'anomena subjecte. Com es veu en les seves paraules, el subjecte està constituiit per la «fuerza de la exclusión y la abyección, una fuerza que produce un exterior constitutivo del sujeto, un exterior abyecto que, después de todo, es "interior" al sujeto como su propio repudio fundacional» (Butler, 2008: 20). Entenem, segons assenyalen Freixas Farré i Juliano Corregido (2008), que és aquesta lògica de la jerarquia la que produeix una vida de marginació social.

Segons García Reyes (2013), les dones trans (i entenem que aquestes declaracions també dialoguen amb l'experiència travesti) s'identifiquen amb aquelles persones que van néixer amb les característiques biològiques associades a 
l'univers masculí. No obstant això, construeixen la seva identitat segons les pràctiques femenines, transgredint la linealitat entre sexe, gènere i desig, amb la qual cosa esdevenen un cos abjecte. Com assenyala l'autora, no hi ha cap continent en el qual les condicions de vida dels individus trans siguin reconegudes políticament ni socialment ${ }^{14}$. L'absència d'una condició de ciutadania suposa per a ells una situació constant de violència estructural que, en la majoria dels casos, culmina amb persecució, maltractaments i mort.

Segons García Reyes (2013), la vida espacial d'aquestes dones trans té lloc segons la criminalització de la seva identitat, com a conseqüència de la incapacitat de les institucions socials per garantir-ne els drets bàsics.

L'experiència de violència estructural de travestis i trans no es refereix exclusivament a la violència física o psicològica, sinó que també està relacionada amb la violència econòmica, que obliga aquestes persones a exercir la prostitució.

Considerem que la violència econòmica es maximitza a Espanya com a conseqüència de la gran recessió espanyola iniciada l'any 2007 (Bentolila et al., 2012; Ferreiro i Serrano, 2012).

Per tant, corroborant les declaracions de Juliano Corregido (2012), les condicions de vida es veuen alterades per la crisi econòmica, la qual cosa produeix canvis en les pràctiques de supervivència dels migrants i, en el nostre cas, travestis i dones trans llatinoamericanes residents a Barcelona.

El 2007 Espanya elabora la Llei d'identitat de gènere, que produeix alteracions formals en les condicions de vida de les dones trans (García Reyes, 2013). Així i tot, segons García Reyes (2013), no s'hi visualitza una transformació de la iniquitat social que va més enllà de la perspectiva formal. L'existència de les travestis i de les dones trans es veu creuada per espais prohibits i per espais de reproducció social relacionats amb l'activitat de la prostitució, locals d'exclusió i d'acollida, al llarg de processos contradictoris i complementaris. La capacitat de prohibició socioespacial proporciona l'enfortiment de l'activitat de la prostitució, atès que aquest és un àmbit que els possibilita reconeixement social, sigui com sigui. Com mostra Ornat (2009), exclusió i inclusió no són oposats, sinó complementaris, atès que formen una vivència espacial paradoxal de travestis $\mathrm{i}$ dones trans en activitats de prostitució.

Segons les afirmacions realitzades per Boulevard (2013), Lee (2013), Nikaratty (2013) i Riquelme (2013), la geografia de les travestis i de les dones trans és feta per exclusió, per prohibició espacial i per violència. Tanmateix, també està feta per la lluita per la supervivència. Segons Boulevard (2013: 79), la vida de les dones trans és una lluita sense fi: «lluita contra la mort, lluita contra els prejudicis, lluita per la supervivència». Aquestes discussions evidencien també que la prostitució és una activitat que forma part de l'existència de diverses travestis i dones trans. Aquesta activitat té un costat pervers, però també un de positiu pel que fa la possibilitat d'ascendir socialment, la qual ha estat sobrevinguda pels guanys que pot proporcionar la prostitució. Com afirma Nikaratty

14. Primera Conferència Internacional d'Identitat de Gènere i Drets Humans, organitzada a Barcelona el mes juny de 2010 (García Reyes, 2013). 
(2013), el seu somni era venir a Europa i aconseguir els diners que li permetessin costejar dos apartaments mitjançant l'exercici de la prostitució, perquè al retornar no hagués de dependre més d'aquesta activitat. D'acord amb aquesta reflexió, les travestis i les dones trans han bastit ponts de desplaçament entre l'Amèrica Llatina i Espanya que estan relacionats amb amigues que varen tenir èxit en l'exercici de la prostitució espanyola, i això els facilita que s'incorporin a aquesta activitat.

Aquesta afirmació es relaciona amb el que defensa Juliano (Lurbe, 2000), ja que la migració no és un fenomen asexuat. $\mathrm{Al}$ contrari, està relacionat amb el gènere i les sexualitats. Aquesta discussió apunta que la migració fa referència a l'ocupació de llocs de treball que la població receptora rebutja. Així doncs, existeixen avantatges espacials relacionats amb el moviment migratori. Tal com assenyalen Silva i Ornat (2014), aquests avantatges estan relacionats amb el lucre de l'activitat de la prostitució en el territori espanyol.

Si l'activitat de la prostitució té relació amb el funcionament del gènere com a mecanisme, és també una de les estratègies de supervivència que desenvolupen les travestis i les dones trans per fer front a l'actuació del sistema del capital, que és incapaç de treballar d'acord amb una perspectiva d'igualtat substantiva, i encara més després de l'inici de la gran recessió espanyola que va tenir lloc els anys 2007 i 2008. Comprenem el gènere com a sistema del capital pel que fa als mecanismes d'opressió, atès que es tracta de mètodes que permeten controlar operacions dels cossos. Així doncs, a partir de la imaginació propiciada per les afirmacions de Scott (1995), en diàleg amb Hartmann (1976), s'afirma que el sistema de capital i el mecanisme de gènere, encara que siguin dos mecanismes distints, estan relacionats. A més, com que no hi ha res que sigui casual, es donen trobades situades que produeixen experiències contextuals (Kelly, 1979). Seguint Foucault (1977), podem afirmar que aquests mecanismes realitzen una subjecció constant de les persones mitjançant una imposició de docilitat o d'utilitat. Cal assenyalar que, segons l'autor, cada mecanisme està relacionat amb una formació específica del saber i amb un exercici específic del poder.

Tractant-se del sistema del capital, tal com es veu a l'afirmació de Mészáros (2002: 268), «seria un miracle si el "microcosmos" del sistema del capital fos ordenat segons el principi d'igualtat real. En conjunt, aquest sistema no pot mantenir-se sense reproduir, amb èxit i de manera constant, les relacions de poder històricament específiques». Així doncs, per l'autor, la constitució del sistema de capital, feta per personificacions del treball, del capital i de l'Estat, no pot ser més que la pròpia perpetuació d'un conjunt d'injustícies fonamentals.

Entenem que les pràctiques espacials de supervivència, que són elaborades per travestis i dones trans llatinoamericanes residents a la ciutat de Barcelona, tenen relació amb la crisi de funcionament del sistema del capital a Espanya, però també com a funcionament del mecanisme de gènere, per dos motius. Primerament, pel fet que comprenen un grup que és dissident respecte a la linealitat entre sexe, gènere i desig, $i$, per tant, dialogant $\mathrm{amb}$ el funcionament del mecanisme de gènere. Així doncs, comprenem aquesta relació, sustentada en les afirmacions de Butler (1997). Segons l'autora, existeix, d'una banda, 
una objecció marxista respecte als estudis culturals com si la problematització de la cultura disminuís el marxisme. D'altra banda, l'autora identifica una tendència a relegar la comprensió de nous moviments socials a l'esfera del cultural, preocupant-se del que ella anomena «merament cultural» $\mathrm{i}$ interpretant aquestes polítiques culturals dividides en faccions, de forma particularista.

Segons l'autora, el focus cultural de la política d'esquerra va abandonar la comprensió materialista i marxista, perquè no va tractar l'equitat econòmica $o$ de redistribució de la riquesa produïda. Va fallar per no situar la cultura en termes de comprensió sistemàtica dels tipus de reproducció social. Segons Butler (1997), aquesta configuració neix de la presumpció que el postestructuralisme impedeix el marxisme i que qualsevol possibilitat de comprendre la vida social de manera sistemàtica es veu perjudicada per una interpretació que considera que el postestructuralisme és destructiu, relativista i políticament paralitzant. Neix d'una distinció estable entre la vida material i la cultural.

Per tant, la nostra problemàtica se sosté en l'afirmació que la vivència de les travestis i de les dones trans no està relacionada amb el món «merament genderitzat o sexualitzat». Aquest gènere, entès com a mecanisme, no és derivat $o$ secundari respecte al funcionament del sistema de capital i de la seva situació de crisi a Espanya, sinó que s'hi relaciona constituint uns mecanismes d'opressió que tenen com a resposta l'establiment de pràctiques espacials de supervivència realitzades per travestis i dones trans a Barcelona.

\section{Les pràctiques espacials de supervivència de travestis i dones trans llatinoamericanes a Espanya, i més enllà}

Les argumentacions d'aquest debat es basen en els resultats de la realització d'una entrevista amb la coordinadora de l'agència ABITS per a l'abordatge integral del treball sexual i una altra amb la regidora de Feminismes i LGTBI (Lesbianes, Gais, Transsexuals, Bisexuals i Intersexuals) / Regidoria de Districte de SantsMontjuïc, de l'Ajuntament de Barcelona; dotze registres de diaris de camp al districte de les Corts, als voltants del Camp Nou —estadi del Futbol Club Barcelona-, on té lloc la pràctica de la prostitució de carrer per part de travestis i dones trans; a més de l'anàlisi de les dades recollides a Erosguía i Mileroticos, webs espanyoles d'anuncis relacionats amb l'exercici de la prostitució. A partir dels dotze treballs de camp realitzats a través d'un període de voluntariat a l'organització no governamental Metges del Món, Catalunya, va ser possible cartografiar les nacionalitats i la pròpia organització espacial de l'exercici de la prostitució al Camp Nou, com es veu als gràfics 2 i 3 i a l'organització espacial respectiva.

Tal com s'ha vist als gràfics 2 i 3, aproximadament el $70 \%$ de les dones trans que exerceixen la prostitució al Camp Nou són migrants (gràfic 2). Pel que fa referència específicament a cada nacionalitat (gràfic 3), les principals són, percentualment, les peruanes, les veneçolanes, les colombianes i les brasileres. En destaca el fet que, del total de persones que exerceixen la prostitució, hi trobem un màxim de 29 dones trans el dia 26 d'agost i un mínim de 14 el dia 20 de setembre de 2016. 
Gràfic 2. Distribució relativa de les dones trans en l'activitat de prostitució a l'àrea del Camp Nou. Informació detallada per dia de treball de camp i segons si són espanyoles o immigrants

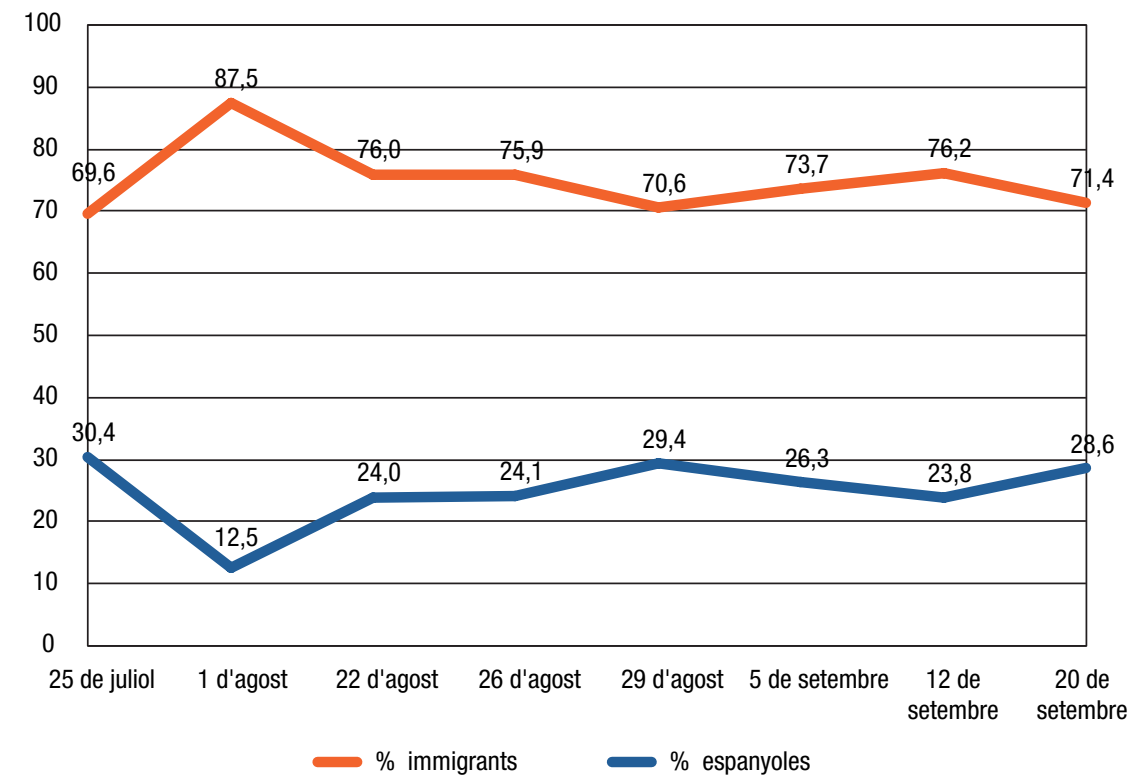

Font: treball de camp realitzat al Camp Nou entre els dies 25 de juny i 12 de setembre de 2016.

Gràfic 3. Dones trans en l'activitat de prostitució a l'àrea del Camp Nou. Informació detallada per dia de treball de camp i segons si són espanyoles o immigrants

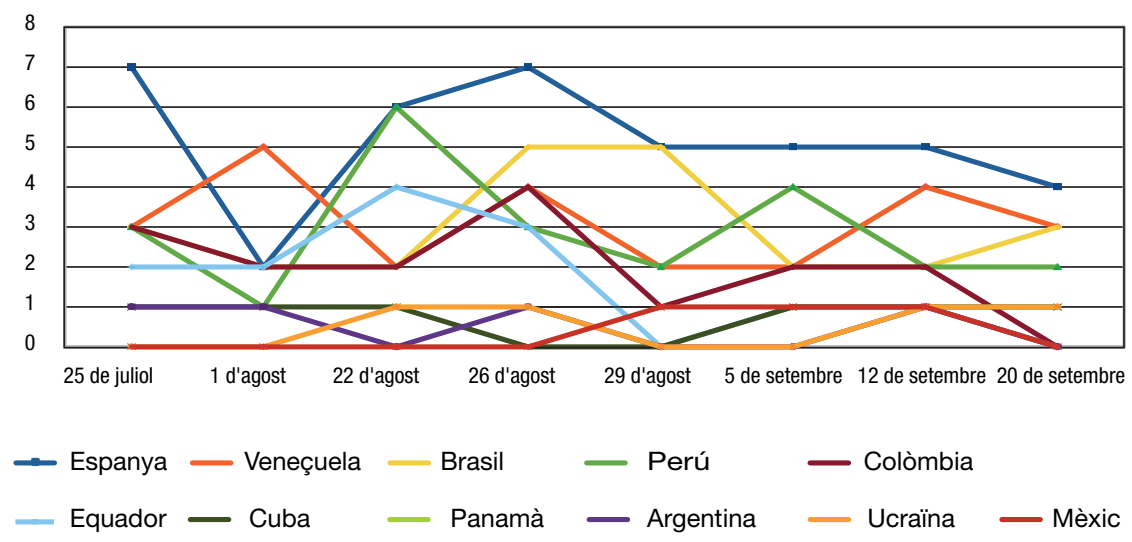

Font: treball de camp realitzat al Camp Nou entre els dies 25 de juny i 12 de setembre de 2016. 
Figura 2. Organització geogràfica de la prostitució trans per nacionalitats. Àrea del Camp Nou

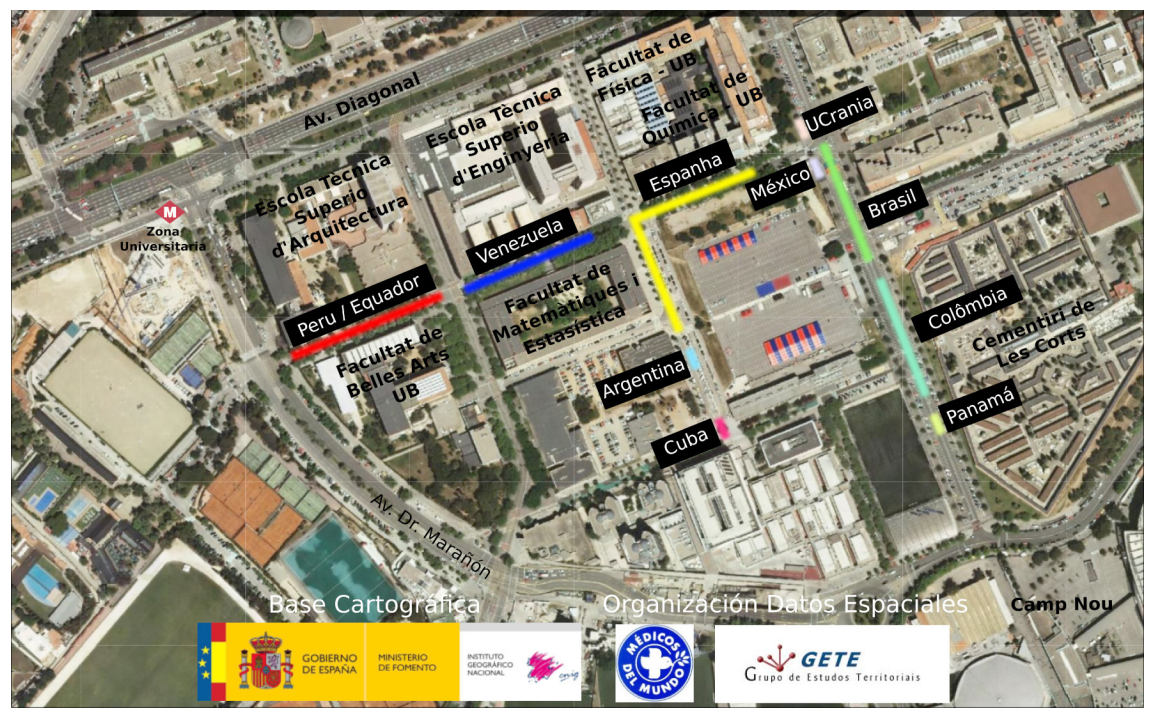

Font: treball de camp realitzat al Camp Nou entre els dies 25 de juny i 12 de setembre de 2016.

Respecte a la cartografia realitzada sobre l'organització espacial de l'exercici de la prostitució de travestis i dones trans al Camp Nou, la vivència d'aquesta espacialitat per a la recollida de les dades de camp, i tal com s'ha evidenciat en les converses mantingudes, tant amb la coordinadora de l'agència ABITS com amb la regidora de Feminismes i LGTBI de l'Ajuntament de Barcelona, les informacions recollides evidencien que, encara que el grup fos petit, les dones trans que exerceixen la prostitució al Camp Nou treballen molt. També, a partir de l'observació del treball de camp, se les veu entrar i sortir dels cotxes constantment. En dues hores fan al voltant de quatre programes i tornen a casa seva amb uns 400 euros, la qual cosa posa de manifest que la demanda establerta en aquest lloc és de dones amb penis, atès que la majoria de les que hi ha no són operades.

Específicament en relació amb l'expressió dona trans, segons una coordinadora de l'agència ABITS, a Espanya s'entén que aquestes persones ja estan en un procés transsexualitzador a partir del moment en què inicien la ingesta d'hormones. A Espanya el terme travesti s'entén com a crossdresser, un home que es vesteix amb roba femenina. Així, tota persona que comença una transformació del seu cos mitjançant la utilització d'hormones, la col-locació de silicona o la realització de depilacions ja es troba en un procés transsexualitzador.

Tal com s'ha dit a l'inici d'aquesta reflexió, la vivència quotidiana de travestis i de dones trans que exerceixen l'activitat de la prostitució dialoga amb l'organització espacial on es desenvolupa aquesta activitat i amb les legislacions que regulen l'ús i l'ocupació de l'espai públic. 
Més enllà del fet que l'exercici de la prostitució a Barcelona té lloc majoritàriament al districte de les Corts ${ }^{15}$ —específicament als voltants del Camp Nou-, un element que hem de considerar en aquesta comprensió fa referència a la disposició, l'any 2006, d'una ordenança municipal que regula l'ús de l'espai públic en aquesta ciutat. Aquesta ordenança estableix les mesures necessàries per fomentar i garantir la convivència ciutadana.

Tanmateix, a més d'un conjunt de normes d'ús de l'espai públic, els articles 39 i 40 d'aquesta ordenança també hi prohibien l'exercici de la prostitució. Concretament, l'article 39 especifica que (1) «està prohibit oferir, sol-licitar, negociar o acceptar, directament o indirectament, serveis sexuals pagats a l'espai públic», especialment a (2) «espais situats a menys de dos-cents metres de distància dels centres educatius on s'imparteixen ensenyaments del sistema general del sistema educatiu».

A l'article 40, el decret estableix les sancions relacionades amb aquesta acció: (2) «Els agents de l'autoritat o serveis municipals [...] es limitaran primer a recordar a aquestes persones que aquestes pràctiques estan prohibides per aquesta Ordenança».

Aquest mateix article estableix que, si s'insisteix a practicar aquesta activitat prohibida sense abandonar el lloc, s'iniciarà el procediment administratiu sancionador i es multarà amb 750 euros. En cas de reiteració, es considerarà falta molt greu i s'aplicaran multes per valor de 1.500 a 3.000 euros.

Cal destacar que aquesta regulació multava tant les persones que oferien serveis sexuals com les que contractaven aquests serveis.

Tal com es mostra a l'entrevista realitzada amb la regidora de Feminismes i LGTBI, encara que l'ordenança va ser elaborada l'any 2006, es va començar a aplicar el 2012, se seguia el consens polític a Barcelona que la prostitució era una activitat que hauria de ser abolida, i no protegida.

Els relats compilats al diari de camp indiquen que algunes travestis brasileres havien contret deutes per un import de 30.000 euros amb l'Ajuntament de Barcelona, atès que els seus llocs d'exercici de la prostitució es trobaven a l'anomenada zona universitària, a poca distància de les facultats de la Universitat Politècnica de Catalunya (l'Escola Tècnica Superior d'Arquitectura de Barcelona, l'Escola Tècnica Superior d'Enginyeria Industrial de Barcelona, l'Escola Politècnica Superior d'Edificació de Barcelona, la Facultat de Matemàtiques i Estadística i el Barcelona Knowledge Campus), totes localitzades al Camp Nou.

Per tant, és lògic entendre que aquesta ordenança municipal hagi interferit en la lògica de l'activitat de la prostitució al Camp Nou, la qual cosa explica en part el reduït nombre de dones trans que hi treballen actualment.

Tal com s'explica a l'entrevista realitzada a la coordinadora de l'agència ABITS, a Espanya no hi ha cap legislació que prohibeixi la prostitució, ni cap llei que protegeixi les persones involucrades en aquesta activitat, però es manté la prohibició del proxenetisme i del tràfic d'éssers humans amb la finalitat d'explotar-los sexualment.

15. Les Corts és un dels districtes de Barcelona amb més valor al mercat immobiliari. 
Segons comenta la coordinadora, després de l'aprovació d'aquesta ordenança, diversos municipis en van aprovar de similars, principalment poblacions de les zones costaneres de Catalunya, que reben un gran nombre de turistes.

Tal com s'assenyala en aquesta mateixa entrevista, encara que les travestis i les dones trans exerceixin l'activitat de la prostitució al Camp Nou, no viuen en aquest lloc, atès el valor dels immobles. Per tant, és evident que es mouen en espais físics molt limitats a les relacions socials que estableixen a través de la seva feina. Així doncs, el desplaçament espacial és una de les seves pràctiques de supervivència.

En relació amb una pràctica espacial específica anomenada «territori discontinu paradoxal de la prostitució travesti» (Ornat, 2013), del 100\% de les ciutats que havien estat llocs de prostitució travesti en el moment de realitzar aquesta investigació, el 26,89\% estaven relacionades amb altres països a més del Brasil, com ara Alemanya, Argentina, Espanya, França, Itàlia, Portugal i Suïssa. En el cas de les ciutats espanyoles que s'indiquen com a llocs d'exercici de la prostitució, hi trobem Barcelona, Bilbao, Gran Canària, Laguna de Duero, Las Palmas, Marbella, Madrid, Màlaga, Múrcia, Oviedo, Puerto de la Cruz, Reus, Salamanca, Santander, Santa Cruz de Tenerife, València i Saragossa. En el cas de les ciutats italianes, s'indiquen Bérgamo, Brescia, Milà, Piacenza i Roma.

Aquesta altra manera de practicar la prostitució també va ser indicada al llarg de les entrevistes amb la regidora de Feminismes i LGTBI i amb la coordinadora de l'agència ABITS, segons la qual es produeix un gran desplaçament de travestis i de dones trans que viuen de la prostitució a Barcelona entre les ciutats de Madrid, Milà, París i Vigo. Per tant, són semblants als trasllats que realitzen les travestis al Brasil entre ciutats d'aquest mateix país (Ornat, 2013). L'agència ABITS també ha trobat una complexa xarxa de connexió amb Itàlia que està estructurada a partir d'una persona resident a Barcelona que porta travestis i dones trans de l'Amèrica Llatina a Espanya, amb la qual cosa estableix un pont entre l'Amèrica Llatina, Barcelona i Itàlia. Aquesta articulació espacial relaciona Veneçuela, Brasil, Espanya (Barcelona) i Itàlia.

Una altra connexió espacial indicada en aquesta entrevista relaciona les ciutats de Barcelona i Madrid, Milà i Florència, el nord d'Itàlia i Montpeller i Marsella, a França. Segons aquesta entrevistada, la característica de connexió espacial estava relacionada amb el tema de la documentació, pel fet que moltes travestis o dones trans que no disposaven de documents farien el desplaçament amb autobús a causa del menor control de la policia fronterera i de la facilitat de fer un desplaçament espacial nocturn entre ciutats en un temps de dotze a catorze hores. Les travestis $\mathrm{i}$ les dones trans que es desplacen cap a Itàlia i França serien doncs dones trans documentades.

Segons la regidora de Feminismes i LGTBI, i d'acord amb els treballs realitzats per l'Ajuntament de Barcelona, s'havia trobat un apartament on vivien set trans llatines que exercien la prostitució de luxe. D'acord amb les explicacions d'aquesta persona, aquest apartament experimentava una rotació quasi setmanal. En conversa amb aquestes dones trans, es va assenyalar que aquest apartament era un punt de connexió espacial entre Barcelona i les illes gre- 
gues. Així doncs, aquests apartaments serien una connexió entre una pràctica espacial d'exercici de la prostitució relacionada amb la prostitució de carrer i la relacionada amb els anuncis.

Sobre aquesta pràctica espacial de l'exercici de la prostitució, vam recollir informacions localitzades en dues webs espanyoles d'anuncis anomenades Erosguia $^{16}$ i Mileroticos ${ }^{17}$. Concretament, a la web Erosguía es van trobar un total de 76 anuncis durant el període de recollida, i a la web Mileroticos se'n van trobar prop de 50 dintre de la mateixa etapa. Dels anuncis que hi havia a les dues webs que contenien informació d'autoidentificació ${ }^{18}$, el $81 \%$ de les dades estaven relacionades amb els termes travesti $\mathrm{i}$ trans. Com ja s'ha comentat al present article, hi ha una plasticitat entre els termes dona trans, travesti i trans, assenyalant el fet que aquestes denominacions varien segons els espais habituals de la vida quotidiana (Missé, 2012; Massey, 2008; McDowell, 1999; Butler, 2003).

Respecte a la nacionalitat o a la regió d'origen, en un percentatge considerable d'anuncis aquesta informació no hi sortia ${ }^{19}$. No obstant això, en relació amb el que indicaven aquestes dades, la distribució era la següent: Brasil, un 34,78\%; Espanya, un 17,39\%; Veneçuela, un 15,22\%; l'Amèrica Llatina, un 8,70\%; Colòmbia, un 8,70\%; Carib, un 6,52; Mèxic, un 4.35\%; Paraguai, un 2,17\%, i Puerto Rico, un 2,17\%. És evident que la suma dels percentatges relacionats amb l'Amèrica Llatina suposa el 82,61\% del total. A més d'aquesta informació, les dades referents a l'edat indicada a l'anunci ${ }^{20}$ mostren que el grup és considerablement jove, perquè està situat en un rang que oscil.la entre els $18 \mathrm{i}$ els 35 anys (de 18 a 20 anys, un 9,21\%; de 21 a 30 anys, un 86,84\%, i de 31 a 35 anys, un 3,95\%).

Concretament, en referència a les ciutats indicades en el conjunt d'anuncis, en totes dues webs n'hi apareixien 44 d'espanyoles, 15 de les quals mostraven una intensitat superior al 2\%. Eren Palma de Mallorca (un 11,1\%), Madrid (un 10,3\%), Barcelona (un 5,6\%), Girona (un 4,8\%), Lleida (un 3,8\%),

16. <http://www.erosguia.com/>. La cerca es fa a partir de Menú > Travestis. Tot i així, a cada anunci pot donar-se una correspondència amb aquest terme o la utilització d'altres termes, com ara, per exemple, trans. Aquesta web existeix des de 2004. Els anuncis alteraven les seves posicions cada dia d'accés a la web. Dades recollides entre el 30 de juny de 2016 i el 7 de juliol de 2016.

17. <https://www.mileroticos.com/>. La cerca va ser realitzada a partir de Travestis en España $>$ Menú > Travestis > Elige Provincia. En el moment de fer-ne la recollida de la informació, al peu de pàgina hi constava el missatge següent: «Suma de anuncios publicados y anuncios subidos a primera posición». La publicació de l'anunci és gratuïta. Tot i així, hi ha venda de lots de visibilitat (Anuncio Top, Destacado i Subir Automático). Dades recollides entre el 30 de juny de 2016 i el 7 de juliol de 2016. Encara que no han estat objecte de recollida de dades, hi ha unes altres webs per a la prostitució de travestis i dones trans a Espanya: Nuevoloquo, Pasion, Sexobarato, Taiakashemales, Teletravesti, Travestiguide, Travestipro i LidereScort. El volum de les webs mostra la importància i la intensitat dels contactes entre travestis i dones trans i clients.

18. Un $30,95 \%$ dels anuncis no tenia aquesta informació.

19. Un $63,49 \%$ dels anuncis no tenia aquesta informació.

20. Un 39,68\% dels anuncis no tenia aquesta informació. 
València (un 4,8\%), Alacant (un 4,0\%), Eivissa (un 4,0\%), Màlaga (un 4,0\%), Bilbao (un 2\%), Sant Sebastià (un 3,2\%), Sevilla (un 3,2\%), Tarragona (un $2,4 \%$ ) i Terrassa (un 2,4\%) ${ }^{21}$.

Així, segons la informació obtinguda a les entrevistes realitzades amb la coordinadora de l'agència ABITS i amb la regidora de Feminismes i LGTBI, aquests llocs no funcionen com a punts fixos, sinó que són un element més de la complexitat de la prostitució de travestis i dones trans llatinoamericanes a Barcelona i més enllà, ja que el desplaçament espacial, considerat com un dels elements de les pràctiques espacials d'aquestes persones, no està relacionat només amb Espanya, sinó també amb diversos països d'Europa, tal com s'ha indicat anteriorment.

Durant una recerca realitzada entre 2008 i 2011 (Ornat, 2011), es van entrevistar 19 travestis que vivien de la pràctica de la prostitució al sud del Brasil, moltes de les quals havien tingut experiència en l'activitat de la prostitució a Europa o coneixien travestis que havien viscut aquesta experiència.

Aquestes entrevistes es van realitzar entre els anys 2008 i 2010, per tant, més enllà del seu contingut, la informació facilitada dialoga profundament amb la proposta d'aquesta reflexió. La travesti anomenada Atena ${ }^{22}$ havia indicat que en deu anys havia ajudat més de cent travestis a desplaçar-se a Europa. Afrodite ${ }^{23}$ va afirmar a la seva entrevista que havia viscut cinc anys a Europa, i que va ser per aquesta experiència, que també era de millora de les condicions de vida, que «es van obrir les portes, tots els braços oberts, i vaig tornar amb una situació financera millor, comprant casa, comprant cotxe, comprant això i allò, comprant regals, amb ajuda». Aquesta millora va suposar un estalvi de 10.000 dòlars americans i la possibilitat d'adquirir béns als quals abans li era impossible accedir. A la seva entrevista, Tetis ${ }^{24}$ va indicar:

[...] hi ha paies que van a Itàlia i que es fan riques en tres mesos, n'hi ha d'altres que es fan riques en tres anys i n'hi ha d'altres que en porten trenta, així que és ràpid i no és ràpid. N'hi ha algunes que triguen molt més temps $\mathrm{i}$ d'altres que ni ho aconsegueixen.

Dione $^{25}$ va explicar a la seva entrevista que havia entrat a Europa per Portugal l'any 1991 (recordem que tant Portugal com Espanya van ingressar a

21. Les altres ciutats d'Espanya amb un percentatge d'informació en anuncis inferiors al $2 \%$ eren: Algesires, Burgos, Cabanes, Castelló de la Plana, Còrdova, La Corunya, Gijón, Igualada, Las Palmas, Logroño, Los Cristianos, Lugo, Manresa, Marbella, Menorca, Múrcia, Pamplona, Ponferrada, Roquetas de Mar, Sabadell, Salamanca, Torremolinos, Torrevieja, Vic, Vigo, Vilafranca del Penedès, Vitòria i Saragossa.

22. Amb l'objectiu de protegir aquestes fonts, vam optar per utilitzar noms que es referissin a les figures femenines contingudes a les mitologies grega i romana. Entrevista realitzada amb Atena, al balneari Camboriú/SC/Brasil, el 26 de maig de 2009.

23. Entrevista realitzada amb Afrodite, a Curitiba/PR/Brasil, el 31 de juliol de 2008.

24. Entrevista realitzada amb Tetis, a Florianópolis/SC/Brasil, el dia 25 de maig de 2009.

25. Entrevista realitzada amb Dione, a Londrina/PR/Brasil, el 27 de març de 2009. 
la Unió Europea el 1986) ${ }^{26}$, un moment en què la diferència del benefici en l'exercici de la prostitució entre l'Amèrica Llatina i Europa era immensa. Va relatar també que havia treballat a Portugal, a Espanya, a França, a Itàlia, a Suïssa i a Alemanya. Igual que Afrodite, Eris $^{27}$ va dir que havia construït tota la seva vida a partir del temps que havia exercit la prostitució a Europa:

[...] comprar el meu pis, el meu cotxe, tinc dues cases, una granja, i tot a través de la prostitució. Així que tot ho vaig treure d'Europa. El cost de la vida a Europa és el triple, es guanya més, tens més clients. En aquell moment cobrava en lliures esterlines, les canviava per dòlars i anava estalviant aquests diners.

Si aquests discursos mostrats més amunt feien referència a la dècada de 1990 o a l'inici del segle XXI, el discurs d'Hipòlita ${ }^{28}$ ens presenta el període de transició entre el que era denominat per elles el període de "vaques grasses» i l'inici del període de «vaques magres». A l'entrevista realitzada amb aquesta travesti la seva vivència era concomitant amb la de la seva amiga a Espanya, l'any 2008. Així, segons el seu discurs:

[...] fa cinquanta euros el programa, però paga vuit-cents euros per setmana pel pis, entens? Llavors, per què les travestis que van a Europa no tornen més riques com passava abans? [...] va dir que són cinquanta euros. És dolorós, a Espanya les ciutats són les més difícils per guanyar diners, perquè no et pots quedar al carrer, només al pis, en una agència. Així que és complicat, llavors has de donar vint euros a la dona del pis, va dir que era una víctima.

Així, les pràctiques espacials de supervivència de travestis i de dones trans llatinoamericanes a Espanya es basen en tres grans contextos:

El relacionat amb les experiències transfobiques quotidianes estructurades a l'Amèrica Llatina, la qual cosa en motiva el desplaçament cap a Europa.

La convivència a Barcelona prèvia a l'ordenança municipal de l'any 2006, que prohibeix la prostitució a l'espai públic, i després del començament de l'aplicació de les multes el 2012, la qual cosa, segons el nostre punt de vista, enforteix la tercera situació.

Els anuncis a la xarxa i el desplaçament entre ciutats mitjançant una pràctica específica (Ornat, 2013), a la recerca de conquestes espacials cada vegada més àmplies i de l'enfortiment de la possibilitat de romandre a Europa.

\section{Consideracions finals}

Aquest text analitza les pràctiques de supervivència espacial desenvolupades per travestis i dones trans llatinoamericanes a la ciutat de Barcelona. Al llarg de la reflexió realitzada, parlem sobre persones que viuen un procés diari continu de prohibició

26. <http://europa.eu/european-union/about-eu/countries/member-countries/spain_pt>.

27. Entrevista realitzada amb Eris, a Porto Alegre/RS/Brasil, el 21 de desembre de 2010.

28. Entrevista realitzada amb Hipòlita, a Ponta Grossa/PR/Brasil, el dia 11 de setembre de 2008. 
situacional i d'establiment d'estratègies espacials de supervivència. Una imbricació paradoxal entre llocs prohibits i espacialitat relacionada amb la prostitució.

El desplaçament cap a Europa realitzat per part de travestis i de dones trans llatinoamericanes i, més específicament, cap a Espanya i Barcelona és un dels resultats d'un càlcul basat en la comparació dels beneficis obtinguts amb l'exercici de la prostitució a l'Amèrica Llatina i a Europa. Per tant, aquesta migració no és un fenomen asexuat, ja que es constitueix obtenint avantatges mitjançant el desplaçament en relació amb la rendibilitat de la prostitució a Espanya.

Atès que aquestes experiències espacials interactuen tant amb el funcionament del mecanisme de gènere com amb el sistema de capital, la trobada entre aquests dos mecanismes és contextualitzada i produeix experiències concretes per a persones concretes. En aquest cas, per a travestis i dones trans llatinoamericanes.

Per tant, entenem les pràctiques de supervivència espacial de travestis $\mathrm{i}$ dones trans llatinoamericanes a Espanya a partir de tres situacions principals. La primera situació està relacionada amb una vida quotidiana estructurada a l'Amèrica Llatina d'acord amb un conjunt d'exclusions socials i de prohibicions espacials que motiven, segons la rendibilitat comparativa més gran de l'exercici de la prostitució a Espanya, el desplaçament cap a Europa. No obstant això, cal afegir uns altres elements a aquesta comprensió que conformen unes altres situacions i uns altres contextos d'anàlisi.

Un d'aquests contextos està relacionat amb la vida a Barcelona abans de l'ordenança municipal de 2006 que prohibeix la prostitució a l'espai públic de la ciutat i després de l'inici de l'aplicació de multes l'any 2012, la qual cosa fomenta l'establiment de noves pràctiques espacials per a l'exercici de la prostitució i augmenta les possibilitats de rendibilitat d'aquesta activitat mitjançant la publicitat a la xarxa o fent el que s'anomena "plaça» per part de travestis i dones transsexuals, és a dir, dur a terme un desplaçament entre ciutats, utilitzant una pràctica ja assenyalada en altres investigacions, a la recerca de conquestes espacials cada vegada més àmplies.

No hi ha cap línia divisòria entre aquestes accions. Al contrari, hi ha zones temporals de solapament en les quals un tipus d'exercici de la prostitució disminueix en intensitat de manera concomitant amb l'enfortiment d'una altra modalitat. En aquesta lògica d'establiment de pràctiques de supervivència, cada context posterior a l'entrada a Europa dialoga amb les forces d'expulsió en els llocs d'origen i les forces d'atracció dels llocs de destinació, experimentats abans i després del període de crisi econòmica que va tenir una punta de turbulències financeres a Espanya en els anys 2007 i 2008.

\section{Referències bibliogràfiques}

Bentolila, Samuel; Cahuc, Pierre; Dolado, Juan i Le Barbanchon, Thomas (2012). "Two-Tier Labour Markets in the Great Recession: France versus Spain». The Economic Journal, 122 (562), 155-269.

<https://doi.org/10.1111/j.1468-0297.2012.02534.x>

Boulevard, Gláucia (2013). «Vida de Travesti é Luta! Luta contra a Morte, Luta contra o Preconceito, Luta pela Sobrevivência e Luta por Espaço». A: SILVA, Joseli 
Maria; Ornat, Marcio Jose i CHImIn, Alides Baptista (Jr.) (ed.). Geografias Malditas: Corpos, Sexualidades e Espaço. Ponta Grossa: Toda Palavra, 69-81.

Browne, Kath (2004). "Genderism and the Bathroom Problem: (re)materialising sexed sites, (re)creating sexed bodies». Gender, Place and Culture, 11 (3), 331-346. <https://doi.org/10.1080/0966369042000258668>

Browne, Kath i LiM, Jason (2010). "Trans lives in the "gay capital of the UK"». Gender, Place and Culture, 17 (5), 615-633. <https://doi.org/10.1080/0966369X.2010.503118>

BROwNE, Kath; NASH, Catherine i Hines, Sally (2010). «Introduction: Towards trans geographies». Gender, Place and Culture, 17 (5), 573-577. <https://doi.org/10.1080/0966369X.2010.503104>

BryanT, Karl i VIDAL-OrTIZ, Salvador (2008). «Introduction to Retheorizing Homophobias». Sexualities, 11 (4), 387-396. <https://doi.org/10.1177/1363460708091740>

BuTLER, Judith (1997). «Merely Cultural». Social Text, 52-53, 265-277. $<$ https://doi.org/10.2307/466744>

- (2003). Problemas de Gênero: Feminismo e subversão da identidade. Rio de Janeiro: Civilização Brasileira.

- (2008). Cuerpos que importan: Sobre los limites materiales y discursivos del sexo. Barcelona: Paidós.

Cabral, Vinícius; Silva, Joseli Maria i ORnat, Márcio José (2013). «Espaço e morte nas representações sociais de travestis». A: Silva, Joseli Maria; ORnAT, Marcio Jose i Chimin, Alides Baptista (Jr.) (ed.). Geografias Malditas: Corpos, sexualidades e espaços. Ponta Grossa: Todapalavra, 273-310.

DOAN, Petra (2007). "Queers in the American City: Transgendered perceptions of urban space». Gender, Place and Culture, 14 (1), 57-74. <https://doi.org/10.1080/09663690601122309>

- (2010). "The Tyranny of gendered spaces-reflections from beyond the gender dichotomy». Gender, Place and Culture, 17 (5), 635-654. $<$ https://doi.org/10.1080/0966369X.2010.503121>

Ferreiro, Jesús i Serrano, Felipe (2012). «The Economic Crisis in Spain: Contagion Effects and Distinctive Fators». A: Arestis, P. i SAWyer. M. The Euro Crisis. Londres: Palgrave Macmillan, 235-268. <https://doi.org/10.1057/9780230393547_7>

Foucault, Michel (1977). Vigiar e punir: Nascimento da prisão. Petrópolis: Vozes.

Freixas Farré, Anna i Juliano Corregido, Dolores (2008). «Un sector susceptible de doble marginación: Mujeres mayores que ejercen o han ejercido la prostitución». Anuario de Psicología, 39 (1), 93-100.

GARCía Reyes, Liza (2013). «Putas y trans: ¿Están las mujeres trans en las narrativas sobre la prostitución?». Educación y Humanismo, 15 (24), 54-77.

GIRSHICK, Lori (2008). Transgender Voices: Beyond women and men. Londres: University Press of New England.

Hartmann, Heidi (1976). "Capitalism, Patriarchy, and Job Segregation by Sex». Sings, 1 (3), 137-169. <https://doi.org/10.1086/493283>

HinEs, Sally (2010). «Queerly situated?: Exploring negotiations of trans queer subjectivities at work and within community spaces in the UK». Gender, Place and Culture, 17 (5), 597-613. <https://doi.org/10.1080/0966369X.2010.503116> 
«Informe de la Ponencia sobre la Prostitución de la Comisión Mixta de los Derechos de la Mujer de las Cortes Generales». Boletin Oficial de las Cortes Generales, 379 (24 de maig de 2007).

JULIANO CORREGIDO, Dolores (2012). «Género y trayectorias migratorias en época de crisis». Revista de Sociologia, 97 (3), 523-540. <https://doi.org/10.5565/rev/papers/v97n3.438>

Kelly, Joan (1979). "The Doubled Vision of Feminist Theory: A Postscript to the "Women and Power"». Feminist Studies, 5 (1), 216-227. <https://doi.org/10.2307/3177556>

KnopP, Larry (2004). «Ontologies of Place, Placelessness, and Movement: Queer quests for identity and their impacts on contemporary geographic thought». Gender, Place and Culture, 11 (1), 121-134. <https://doi.org/10.1080/0966369042000188585>

LeE, Débora (2013). «A Geografia de Uma Travesti é uma Barra, é Matar um Leão a Cada Dia». A: Silva, Joseli Maria; Ornat, Marcio Jose i Chimin, Alides Baptista (Jr.) (ed.). Geografias Malditas. Corpos, Sexualidades e Espaço. Ponta Grossa: Toda Palavra, 27-38.

Lurbe, Kàtia (2000). «Mujeres estructuralmente viajeras: Estereotipos y estrategias. Entrevista con Dolores Juliano». Papers: Revista de Sociología, 60, 381-389. <https://doi.org/10.5565/rev/papers/v60n0.1280>

MASSEY, Doreen (2008). Pelo espaço: Uma nova política da espacialidade. Rio de Janeiro: Bertrand Brasil.

MCDOwell, Linda (1999). Gender, Identity and Place: Understanding Feminist Geographies. Mineápolis: University of Minnesota Press.

MÉszarós, István (2002). Para Além do Capital. São Paulo: Boitempo Editora.

Missé, Miquel (2012). La lucha por la despatologización trans y perspectivas de futuro del movimiento trans en Barcelona. Recuperat el dia 16 d'abril de 2015, de <http://fundacionbetiko.org/wp-content/uploads/2012/11/La-lucha-por-ladespatologizaci\%C3\%B3n-trans-y-perspectivas-de-futuro-del-movimientotrans-en-Barcelona.pdf>.

Mott, Luiz; Cerqueira, Marcelo i Almeira, Cláudio (2002). O Crime Anti-Homossexual no Brasil. Salvador: Grupo Gay da Bahia.

NASH, Catherine (2010). "Trans geographies, embodiment and experience». Gender, Place and Culture, 17 (5), 579-595. <https://doi.org/10.1080/0966369X.2010.503112>

NikARATTY, Leandra (2013). "O que mais me marcou na vida é ser barrada e não poder entrar nos lugares: Esta é a geografia de uma travesti». A: SiLvA, Joseli Maria; Ornat, Marcio Jose i Chimin, Alides Baptista (Jr.) (ed.). Geografias Malditas. Corpos, Sexualidades e Espaço. Ponta Grossa: Toda Palavra, 39-55.

Ornat, Marcio Jose (2009). "Espacialidades Travestis e a Instituição do Território Paradoxal». A: SILvA, Joseli Maria (ed.). Geografias Subversivas: Discursos sobre Espaço, Gênero e Sexualidades. Ponta Grossa: Toda Palavra, 177-210.

- (2011). Território descontínuo e multiterritorialidade na prostituição travesti através do Sul do Brasil. Rio de Janeiro: Universidade Federal do Rio de Janeiro. Tesi doctoral.

- (2013). «A Instituição do Território Descontínuo Paradoxal na Atividade da Prostituição Travesti». A: Silva, Joseli Maria; Ornat, Marcio Jose i ChIMIn, Alides Baptista (Jr.) (ed.). Geografias Malditas: Corpos, Sexualidades e Espaço. Ponta Grossa: Toda Palavra, 183-206. 
Ornat, Marcio Jose; SILVA, Joseli Maria (2014). «Território Descontínuo Paradoxal, Movimento LGBT, Prostituição e Cafetinagem no Sul do Brasil». Geousp (USP), $18,113-128$. <https://doi.org/10.11606/issn.2179-0892.geousp.2014.81087>

Riquelme, Fernanda (2013). "A vida da travesti é glamour, mas também é violência em todo lugar». A: Silva, Joseli Maria; Ornat, Marcio Jose i ChImIN, Alides Baptista (Jr.) (ed.). Geografias Malditas: Corpos, Sexualidades e Espaço. Ponta Grossa: Toda Palavra, 55-68.

RoOKe, Alison (2010). "Trans youth, science and art: Creating (trans) gendered space». Gender, Place and Culture, 17 (5), 655-672. <https://doi.org/10.1080/0966369X.2010.503124>

SASSEN, Saskia (2003). Contrageografías de la globalización: Género y ciudadanía en los circuitos transfonterizos. Madrid: Traficantes de Sueños.

SCOTT, Joan (1995). «Genero: Uma categoria útil para a análise histórica». Educação \& Realidade, 20 (2), 71-99.

SILva, Joseli Maria (2009). Geografias Subversivas: Discursos sobre Espaço, Gênero e Sexualidades. Ponta Grossa: Toda Palavra.

- (2013). «Espaço interdito e a experiência urbana travesti». A: Silva, Joseli Maria; Ornat, Marcio Jose i Chimin, Alides Baptista (Jr.) (ed.). Geografias Malditas: corpos, sexualidades e espaços. Ponta Grossa: Todapalavra, 143-182.

Silva, Joseli Maria i ORNAT, Márcio José (2011). «Sobre sexualidade e espaço: Prostituição e território travesti». A: RibeIro, Miguel Angelo i Silva OliveIrA, Rafael da (ed.). Território, sexo e prazer: Olhares sobre o fenômeno da prostituição na geografia brasileira. Rio de Janeiro: Gramma, 167-184.

- (2014). «Intersectionality and transnational mobility between Brazil and Spain in travesti prostitution networks». Gender, Place and Culture, 1-16.

- (2016a). «Sexualities, Tropicalizations and the Transnational Sex Trade: Brazilian Women in Spain». A: Brown, G. i Browne, K. (ed.). Companion to Geographies of Sex and Sexualities. Nova York: Routledge, 331-340.

- (2016b). «Transfeminism and Decolonial Thought: The Contribution of Brazilian Travestis». TSQ: Transgender Studies Quarterly, 3, 220-227. <https://doi.org/10.1215/23289252-3334415>

- (2016c). «Wake up Alice, this is not Wonderland!?: Power, Diversity and Knowledge in Geographies of Sexualities». A: Brown, G. i Browne, K. (ed.). Companion to Geographies of Sex and Sexualities. Nova York: Routledge, 185-194.

- (2016d). «Corporeidade, sexualidades no mercado sexual transnacional sob o olhar eurocêntrico». Geousp (USP), 20, 69-82.

<https://doi.org/10.11606/issn.2179-0892.geousp.2016.98302>

VALENTINE, David (2007). Imagining Transgender-an ethonography of a category. Londres: Duke University. <https://doi.org/10.1215/9780822390213>

WeinberG, George (1972). Society and the Healthy Homosexual. Nova York: St Martin's. 
